\title{
Philippe Portier, Michel Veuille, Jean-Paul Willaime (éd.), Théorie de l'évolution et religions
}

Paris, Riveneuve éditions, coll. « Actes académiques », 2011, 254 p.

\section{Paul Airiau}

\section{(2) OpenEdition}

Édition électronique

URL : http://journals.openedition.org/assr/24693

DOI : $10.4000 /$ assr.24693

ISSN : $1777-5825$

\section{Éditeur}

Éditions de l'EHESS

Édition imprimée

Date de publication : 30 décembre 2012

Pagination : 257

ISSN : 0335-5985

Référence électronique

Paul Airiau, «Philippe Portier, Michel Veuille, Jean-Paul Willaime (éd.), Théorie de l'évolution et religions », Archives de sciences sociales des religions [En ligne], 160 | octobre-décembre 2012, mis en ligne le 26 mars 2013, consulté le 21 septembre 2020. URL : http://journals.openedition.org/assr/24693 ; DOI : https://doi.org/10.4000/assr.24693

Ce document a été généré automatiquement le 21 septembre 2020.

(c) Archives de sciences sociales des religions 


\section{Philippe Portier, Michel Veuille, Jean-Paul Willaime (éd.), Théorie de l'évolution et religions}

Paris, Riveneuve éditions, coll. « Actes académiques », 2011, 254 p.

\section{Paul Airiau}

\section{RÉFÉRENCE}

Philippe Portier, Michel Veuille, Jean-Paul Willaime (éd.), Théorie de l'évolution et religions, Paris, Riveneuve éditions, coll. « Actes académiques », 2011, 254 p. 
1 La remise en cause de la théorie de l'évolution pour des motifs religieux, en particulier dans le cadre scolaire, a conduit à l'organisation d'un colloque réunissant l'École pratique des hautes études (EPHE), l'Institut européen en sciences des religions (IESR), le Groupe sociétés, religions, laïcités (GSRL) et l'Inspection générale de l'éducation nationale (IGEN). Ce volume en produit les actes, avec quinze contributions distribuées en trois volets : l'évolution de la théorie de l'évolution; théorie de l'évolution, religions et conception $\mathrm{du}$ monde; théorie de l'évolution, science, religion et société. Une importante introduction signée des trois éditeurs du volume donne la ligne de force des réflexions, et va au-delà du simple résumé

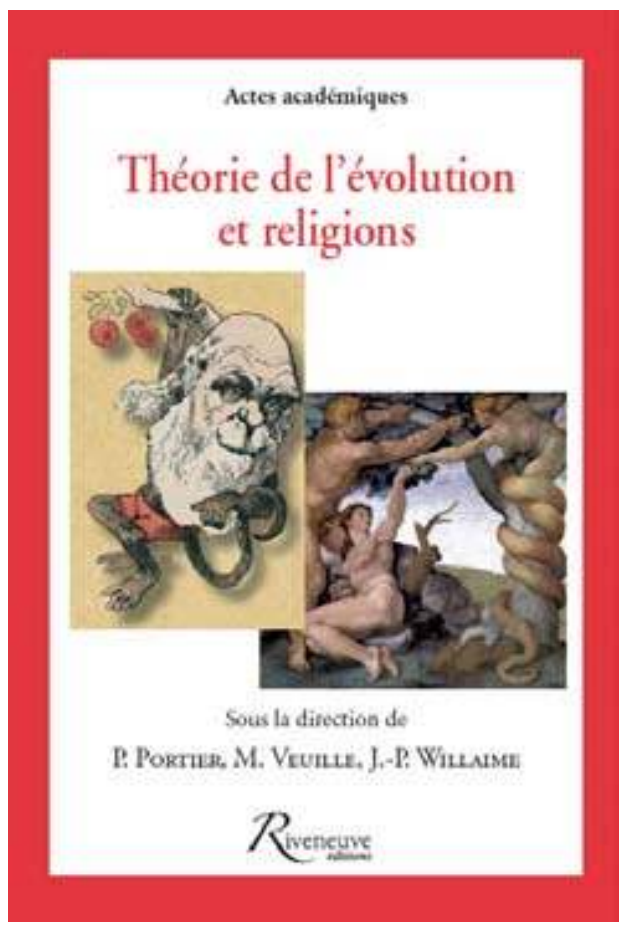
des communications.

2 Les historiens et sociologues des religions, sans doute moins au fait de la pensée darwinienne dans sa construction, sa réception et sa destinée, liront avec profit les présentations scientifiques (Michel Veuille avec un panorama général de l'histoire de la théorie de l'évolution; Thierry Wirth avec une illustration de l'utilité du néodarwinisme en bactériologie) et les analyses d'histoire des sciences de la première partie (Valentine Zuber étudie l'athéisme de Clémence Royer, première traductrice française de Darwin; Laurent Loison et le matérialisme des transformistes français de la fin du XIX ${ }^{\mathrm{e}}$ siècle; Marc Godinot et les relations entre religion et évolution à la fin du $\mathrm{XIX}^{\mathrm{e}}$ siècle). Ils seront plus familiers avec les deuxième et troisième parties, qui se concentrent essentiellement sur la réception chrétienne de Darwin dans les protestantismes (Sébastien Fath avec son panorama des créationnismes protestants; Daniel Becquemont et la position de l'Église anglicane; Roger Pouivet travaille sur la pensée du philosophe calviniste Alvi Platinga) et le catholicisme (Philippe Portier étudie les modalités de transaction du magistère avec l'évolution) - une seule contribution traite du monde musulman, à partir de l'Égypte (Amir Yassin, Héloïse Bastide), une sur l'URSS (Philippe Portier) - et sur les relations contemporaines entre sciences et religions, d'un point de vue théorique (Jean-Paul Willaime creuse ses réflexions sur l'ultra-modernité en l'appliquant à la science désormais désenchantée ; Philippe Gaudin travaille à distinguer vérité scientifique et vérité religieuse), pratique (Séverine Mathieu présente le résultat d'une enquête de terrain sur les relations entre collégiens et théorie de l'évolution) et juridique (Blandine Chélini-Pont expose la jurisprudence étatsunienne sur la théorie de l'évolution).

3 La participation de l'IGEN et de l'IESR à ce colloque explique sans doute des prises de position sur les vérités que doit transmettre l'école et les contre-vérités qu'elle doit rejeter, et sur la nécessaire introduction d'éléments d'épistémologie ou d'enseignement $\mathrm{du}$ fait religieux dans les programmes scolaires (Philippe Gaudin, Séverine Mathieu). Une fois de plus se retrouve ici une double réalité : la situation aporétique de l'école 
dans la démocratie, car elle doit former des citoyens à la liberté intellectuelle par la pratique critique et en même temps transmettre des vérités qui ne peuvent être critiquées, afin que, précisément, l'esprit critique soit transmis; et la nécessité croissante, face à la complexité croissante du monde, d'étendre ce que les élèves doivent connaître, au risque de charger les programmes, de multiplier les approches, et de ne rien approfondir ou maîtriser. L'enseignant du secondaire qui signe ces lignes ne peut s'empêcher de penser que la complexité du réel devrait inciter à plus de modestie, ou alors à une refonte complète de l'enseignement et à une confrontation franche à ses apories. Mais ceci est une autre question, qui n'enlève rien à l'intérêt profond de cet ouvrage. 